\title{
Total Oxidation of Isopropanol in the Liquid Phase, under Atmospheric Pressure and Low Temperature, on Transition Metal Oxides Catalysts $\mathrm{Cr}_{2} \mathrm{O}_{3}$ and $\mathrm{Fe}_{2} \mathrm{O}_{3}$
}

\author{
Younes Dehmani iD and Sadik Abouarnadasse \\ Laboratory of Chemistry and Biology Applied to the Environment, Moulay Ismail University, Faculty of Sciences of Meknes, \\ Meknes, Morocco \\ Correspondence should be addressed to Younes Dehmani; dehmaniy@gmail.com
}

Received 25 March 2020; Revised 25 May 2020; Accepted 26 June 2020; Published 13 July 2020

Academic Editor: José Morillo

Copyright (C) 2020 Younes Dehmani and Sadik Abouarnadasse. This is an open access article distributed under the Creative Commons Attribution License, which permits unrestricted use, distribution, and reproduction in any medium, provided the original work is properly cited.

\begin{abstract}
Isopropanol oxidation in the liquid phase under atmospheric pressure and low temperature has been studied in the presence of transition metal oxides $\left(\mathrm{Cr}_{2} \mathrm{O}_{3}\right.$ and $\left.\mathrm{Fe}_{2} \mathrm{O}_{3}\right)$ prepared by the precipitation method. These solids characterized by structural analyses (FTIR and XRD) and textural analysis (BET) have led to results in line with those reported in the literature. Chromium oxide has a much more developed texture, with a specific surface area and pore volume 5 times larger than iron oxide. Both of the solids show a good specific activity and led to acetone and carbon dioxide to be formed as the only oxidation products of isopropanol. However, chromium oxide is more active. The initial catalytic activity for the latter is varying between $4.87 * 10^{-6}$ and $5.79 * 10^{-6} \mathrm{~mol} \cdot \mathrm{g}^{-1} \cdot \mathrm{s}^{-1}$ with temperature range from 40 to $80^{\circ} \mathrm{C}$. Kinetic study shows that the reaction follows a successive scheme: isopropanol $\longrightarrow$ acetone $\longrightarrow \mathrm{CO}_{2}$ involving a redox mechanism. The low value of the activation apparent energy $\left(\mathrm{E}_{\mathrm{a}} \cdot\left(\mathrm{Cr}_{2} \mathrm{O}_{3}\right)=\right.$ $\left.2.87 \mathrm{~kJ} \cdot \mathrm{mol}^{-1}<\mathrm{E}_{\mathrm{a}} \cdot\left(\mathrm{Fe}_{2} \mathrm{O}_{3}\right)=5.37 \mathrm{~kJ} \cdot \mathrm{mol}^{-1}\right)$ justifies the relatively higher activity observed for chromium oxide.
\end{abstract}

\section{Introduction}

Nowadays, the preservation of air quality has become a priority, as evidenced by the attention and hope to the Copenhagen Conference on climate (2009), which brings together 192 countries. Emissions of pollutants involved in air pollution include volatile organic compounds (VOCs) [1].

Volatile organic compounds are the major air pollutants containing at least the element carbon and one or more other items $[2,3]$. They are characterized by their large volatility (the transition from the liquid state to the gaseous state takes place under normal temperature and pressure) $[4,5]$. Several techniques exist for the reduction of these pollutants: restoratives, which present the advantage of recycling (adsorption, condensation, absorption, and membrane technique) or destructive (catalytic oxidation, thermal oxidation, and biological destruction) [6-9].

The choice of the technique to be used is based on criteria linking at the same time, parameters of pollutants, and environment. When VOCs have weak concentrations, particularly in the aquatic environment, total catalytic oxidation has the advantage to limit the amount of energy spent while working at low temperature and to reduce the cost of pollutant destruction $[1,10]$. This makes the catalytic oxidation the most promising in terms of energy saving.

The oxides of transition metals, such as $\mathrm{Cr}, \mathrm{Fe}, \mathrm{Ni}, \mathrm{Mn}$, $\mathrm{Cu}, \mathrm{Co}, \mathrm{Zn}$, are well known as typical catalysts for hydrocarbons oxidation at high temperature $\left(200-500^{\circ} \mathrm{C}\right)$ in the gas phase or in the liquid phase under high pressure and temperature above $100^{\circ} \mathrm{C}$, but they have never been cited in the literature for the same reactions in the liquid phase, under atmospheric pressure and low temperature, below $100^{\circ} \mathrm{C}[11]$. Thus, they can be very profitable for a complete oxidation of VOCs under these conditions.

The aim of this work is to test the catalytic efficiency of $\mathrm{Fe}_{2} \mathrm{O}_{3}$ and $\mathrm{Cr}_{2} \mathrm{O}_{3}$ in complete oxidation of isopropanol in the liquid phase at low temperature. The choice of isopropanol in this study is based on the classification of the 
latter among VOCs. So, it can contribute to pollution of environment and must be eliminated from liquid rejects.

\section{Experimental Section}

2.1. Catalyst's Preparation. The solids were prepared by the precipitation method. In this process, the nitrates of metals are used as precursors and ammonia $\left(\mathrm{NH}_{4} \mathrm{OH}\right)$ as precipitation agent. The dried powders were calcined at $500^{\circ} \mathrm{C}$ for $3 \mathrm{~h}$.

\subsection{Catalyst Characterization}

2.2.1. X-Ray Diffraction. Patterns were recorded using an X'PERT MPD-PRO wide angle X-ray powder diffractometer provided with a diffracted beam monochromator and $\mathrm{Ni}$ filtered CuK a radiation $(\lambda=1.5406 \AA)$. The $2 \theta$ angle was scanned between $4^{\circ}$ and $30^{\circ}$ range with a counting time of $2.0 \mathrm{~s}$ at steps of $0.02^{\circ}[12]$.

2.2.2. Fourier Transform Infrared. Fourier transform infrared (FTIR) spectra were obtained using a device (Shimadzu, JASCO 4100), in the range of $400-4000 \mathrm{~cm}^{-1}$ [13].

2.2.3. $\mathrm{N}_{2}$ Adsorption-Desorption Measurements. These measurements were performed at $-196^{\circ} \mathrm{C}$, using a Micromeritics ASAP 2010. Specific surface area and the average pore diameter were determined according to the standard BET and BJH (Barrett, Joyner, and Halenda) methods, respectively [13].

2.3. Catalytic Tests. In a three-necked flask of $250 \mathrm{ml}$ capacity, used as a reactor, $0.15 \mathrm{~mL}$ of isopropanol (reactive), $120 \mathrm{mg}$ of catalysts, and $200 \mathrm{~mL}$ of distilled water are introduced successively. The temperature of water bath heating (reaction temperature) is adjusted to the desired value $\left(40^{\circ} \mathrm{C}\right.$, $60^{\circ} \mathrm{C}$, and $80^{\circ} \mathrm{C}$ ) before plunging the reactor in the bath. Air (oxidizing reagent) is then admitted in the reactor using a lateral tubing under a flow of the order $40 \mathrm{~mL} / \mathrm{min}$ (more than enough to make the solution constantly saturated with oxygen). The reaction mixture is stirred continuously for the duration of the test in order to facilitate the accessibility of catalysts' grains to the reagent and to ensure the operation of the catalyst in chemical regime. It should be recalled that each catalytic test was performed with a new test portion of catalysts. The chromatographic analysis was conducted using a device (SHIMADZU CR15A) fitted with a column under the following conditions.

Column temperature is $80^{\circ} \mathrm{C}, \mathrm{P}_{\mathrm{N} 2}=24.525 \mathrm{kPa}$, $\mathrm{P}_{\mathrm{H} 2}=39.24 \mathrm{kPa}$, pair $=49.05 \mathrm{kPa}$, and carrier gas flow right: $\mathrm{D}=40 \mathrm{~mL} \cdot \mathrm{mn}^{-1}$.

\section{Results and Discussion}

\subsection{Catalyst Characterization}

3.1.1. X-Ray Diffraction. Samples of solids, $\mathrm{Cr}_{2} \mathrm{O}_{3}$ and $\mathrm{Fe}_{2} \mathrm{O}_{3}$, calcined at $500^{\circ} \mathrm{C}$ for 3 hours have been analyzed by diffraction of $\mathrm{X}$-rays. The diffractograms obtained are grouped in Figure 1.
Figure 1 shows the X-ray diffraction patterns (XRD) of the prepared materials. The XRD diagram (Figure 1(a)) shows peaks at $2 \theta=24.5,33.5,36.5,41.5,50.5,54.9$, and 65.5 corresponding, respectively, to the reticular planes (llll), $\left.10 \begin{array}{lll}1 & 0 & 4\end{array}\right)$, (1 110$),\left(\begin{array}{lll}1 & 1 & 3\end{array}\right),\left(\begin{array}{lll}0 & 2 & 4\end{array}\right),\left(\begin{array}{lll}1 & 1 & 6\end{array}\right)$, and (3 $\left.\begin{array}{lll}3 & 0\end{array}\right)$ of the hexagonal structure of $\mathrm{Cr}_{2} \mathrm{O}_{3}$ [14]. The XRD iron oxide spectrum lets peaks appear corresponding to $\alpha-\mathrm{Fe}_{2} \mathrm{O}_{3}$. They were observed at $24.1,33.1,35.6,49.5,54.1,58.2,62$, and $64^{\circ}$, which corresponds, respectively, to reticular plans (012), (104), (110), (024), (116), (214), (118), and (441) of hematite [15].

3.1.2. FTIR: Fourier Transform Infrared Spectroscopy. $\mathrm{Cr}_{2} \mathrm{O}_{3}$ and $\mathrm{Fe}_{2} \mathrm{O}_{3}$ solids calcined at $500^{\circ} \mathrm{C}$ for 3 hours have been characterized by FTIR spectroscopy. The obtained spectra are presented in Figure 2.

Figure 2 corresponding to the calcined $\mathrm{Cr}_{2} \mathrm{O}_{3}$ sample spectrum shows bands located at 956, 901, 833, 796, 563, and $500 \mathrm{~cm}^{-1}$ characterizing $\mathrm{Cr}_{2} \mathrm{O}_{3}$. It can also be noted the presence of other bands located at 2423 and $1386 \mathrm{~cm}^{-1}$ attributed to the vibration of $\mathrm{CO}_{2}$ adsorbed form and which comes from the ambient air. On the same spectrum, we note the presence of a band in $1637 \mathrm{~cm}^{-1}$. This band corresponds to the vibration of water's hydroxyl [16]. The $\mathrm{Fe}_{2} \mathrm{O}_{3}$ spectrum lets a relatively strong band appear centered at 500, 630,800 , and $890 \mathrm{~cm}^{-1}$. These bands are attributed to the vibrations of the hematite network. We also note the presence of other strips located at 1350, 1570, and $1650 \mathrm{~cm}^{-1}$, which can be attributed to the vibrations of $\mathrm{CO}_{2}$ and hydroxyl of adsorbed water [15].

3.1.3. Adsorption-Desorption of $N_{2}$-BET. Pore volume distribution and nitrogen adsorption/desorption isotherms of the synthesized catalysts $\left(\mathrm{Cr}_{2} \mathrm{O}_{3}\right.$ and $\left.\mathrm{Fe}_{2} \mathrm{O}_{3}\right)$ are illustrated in Figure 3. The isotherms are of type IV with an $\mathrm{H} 3$ hysteresis loop according to the IUPAC classification. The hysteresis loop was observed at a high relative pressure between 0.8 and 1 , which indicates the presence of pores with large diameters on the prepared samples. The presence of hysteresis loop in the isotherms is associated with the secondary process of capillary condensation, which results in the complete filling of the mesopores at relative pressure P/P 0 below 1 [17]. The results are regrouped in Table 1.

It is important to note the great difference between the textural properties of the two solids. Chromium oxide has a much more developed texture, with a specific surface area 5 times larger than iron oxide, as attested by the results in Table 1, and the X-ray diffractogram (Figure 1), which shows a large continuous background and low intensity of diffraction peaks, indicating that the chromium oxide sample is not well crystallized. This implies particles with small diameter and therefore a better solid division state.

3.2. Catalytic Tests: Catalytic Oxidation of Isopropanol. The chromatograph must be calibrated by each reaction constituent in order to quantify them at any time during the reaction. For this, a calibration curve was traced for each constituent. 


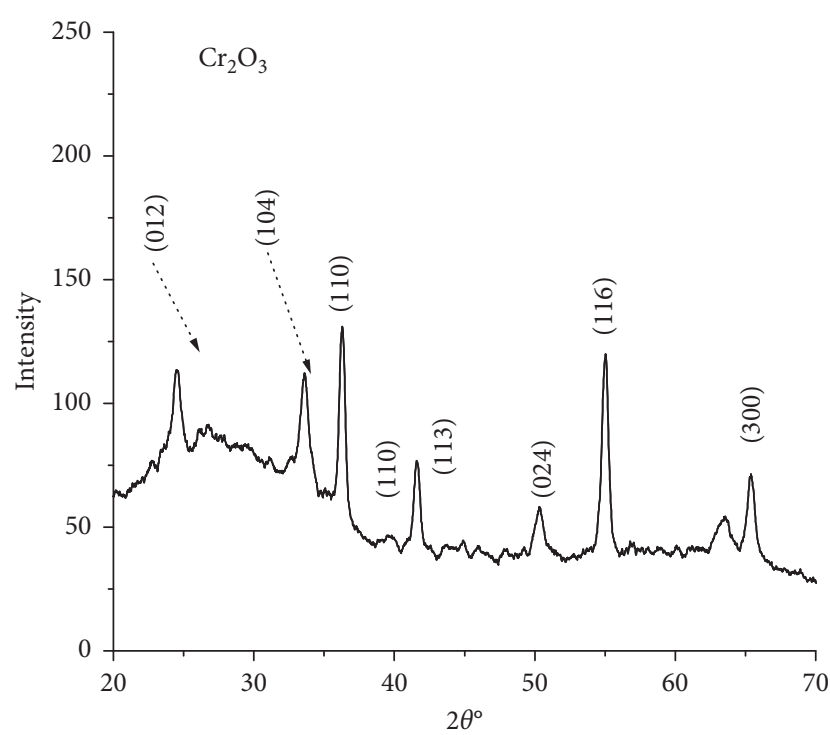

(a)

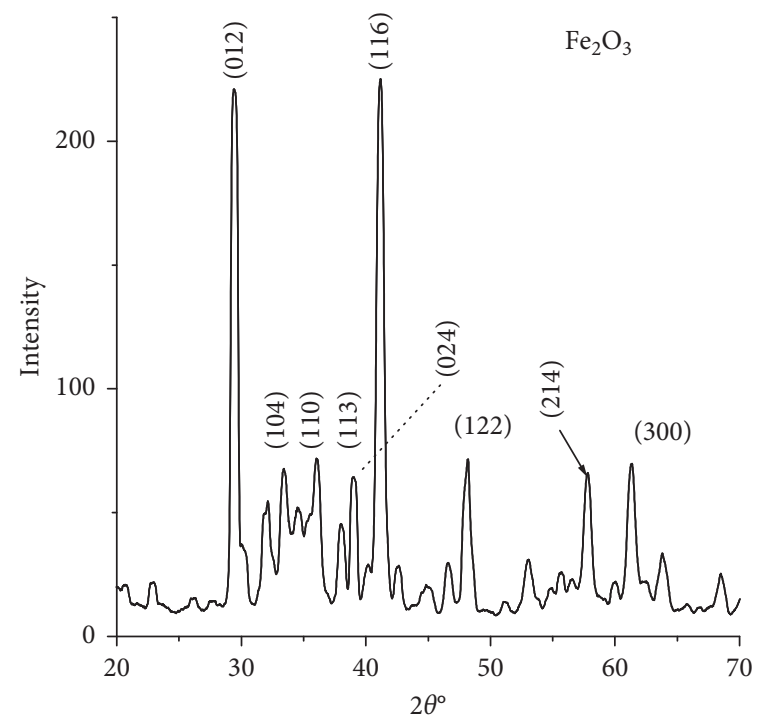

(b)

Figure 1: Diffractograms $\mathrm{Cr}_{2} \mathrm{O}_{3}$ and $\mathrm{Fe}_{2} \mathrm{O}_{3}$.

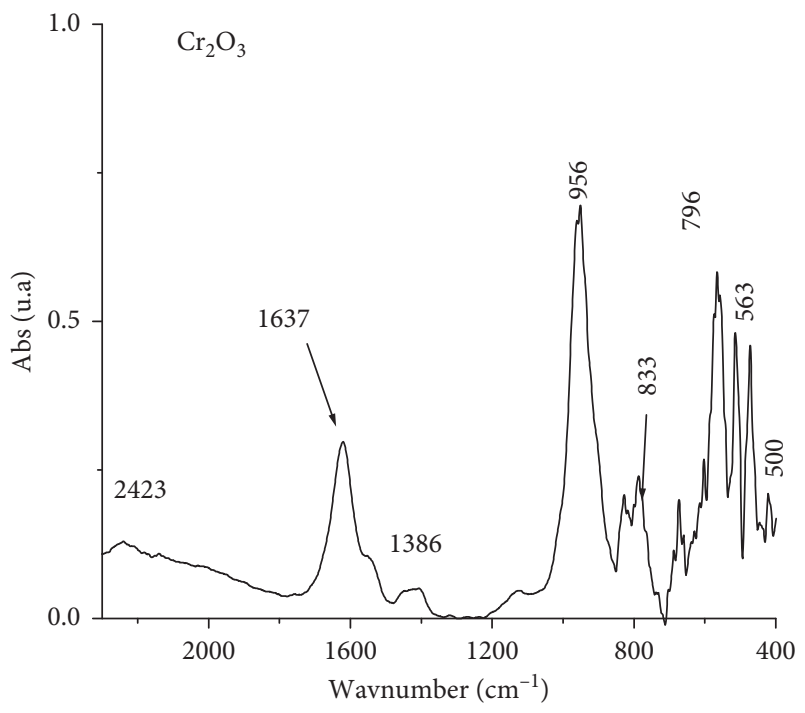

(a)

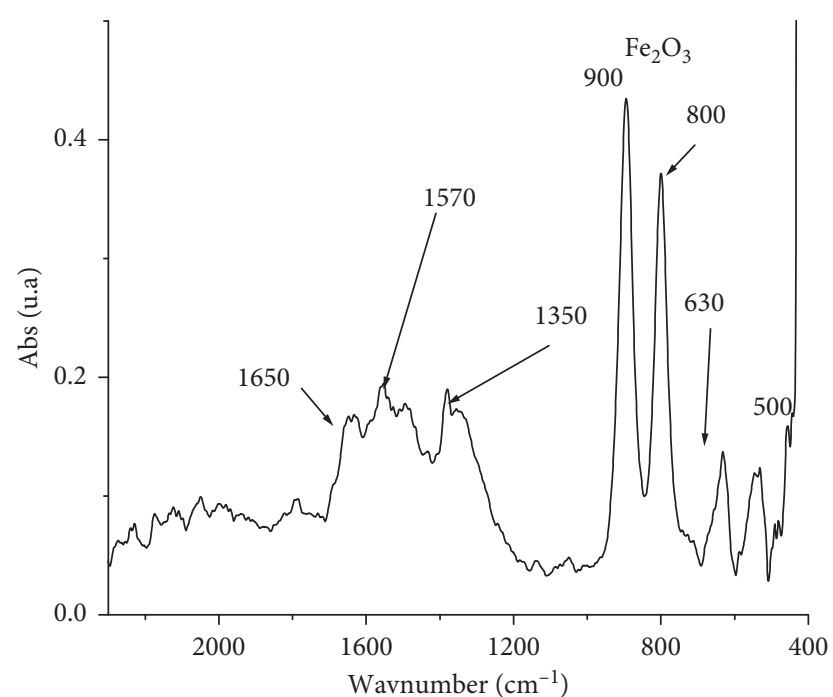

(b)

Figure 2: Infrared spectrum of $\mathrm{Cr}_{2} \mathrm{O}_{3}$ and $\mathrm{Fe}_{2} \mathrm{O}_{3}$.

3.2.1. Blanck Test. The tests without the catalyst in the same conditions of pressure and temperature showed the absence of any activity in homogenous phase [18].

3.2.2. Catalyst Amount Effect on the Specific Activity. The specific activity is defined as the number of moles of isopropanol disappeared by unit time and unit mass of catalyst $[11,19]$ :

$$
a_{\mathrm{s}}\left(\mathrm{mol} \cdot \mathrm{g}^{-1} \cdot \mathrm{s}^{-1}\right)=-\left(\frac{1}{m}\right) \cdot\left(\frac{\mathrm{d} n}{\mathrm{~d} t}\right) .
$$

The influence of the catalyst amount on the specific activity is shown in Figure 4.
It appears that, at the chosen reaction temperature $\left(T=80^{\circ} \mathrm{C}\right)$, the initial specific activity relative to the disappearance of isopropanol keeps a constant value whatever the amount of catalyst. This means that under these conditions, the catalyst operates in chemical regime.

3.2.3. Evolution of Isopropanol Concentration over Time. Catalytic performance tests for the total oxidation of isopropanol were carried out at different temperatures, such as 40,60 , and $80^{\circ} \mathrm{C}$, both on iron oxide and chromium oxide. Results obtained, represented in terms of moles number of isopropanol over time, are shown in Figures 5 and 6. It is important to note that these catalysts, used under the same 


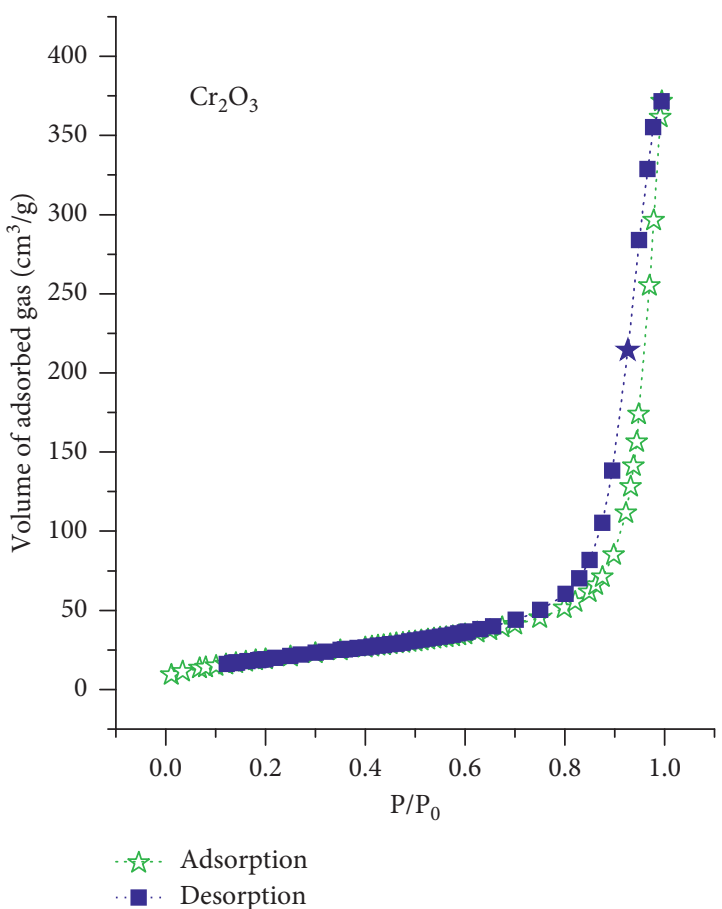

(a)

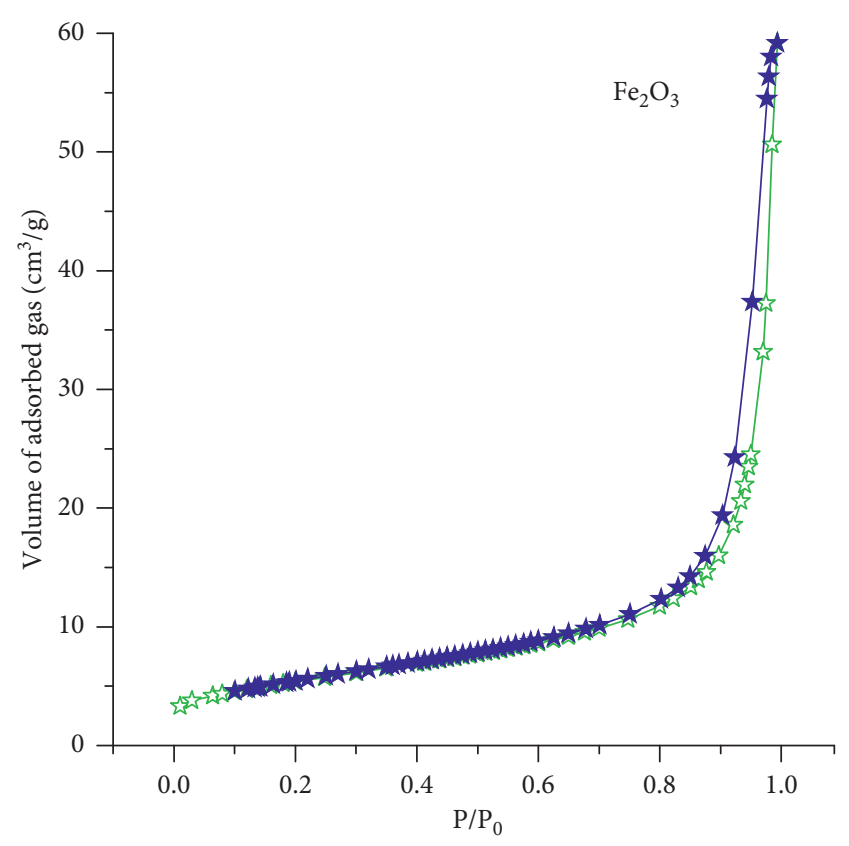

A. Adsorption

-. Desorption

Figure 3: $\mathrm{N}_{2}$ adsorption/desorption isotherms on $\mathrm{Cr}_{2} \mathrm{O}_{3}$ and $\mathrm{Fe}_{2} \mathrm{O}_{3}$.

TABLE 1: Textural characteristics of solids.

\begin{tabular}{lccc}
\hline Solid & $\begin{array}{c}\text { Specific surface } \\
\left(\mathrm{m}^{2} \cdot \mathrm{g}^{-1}\right)\end{array}$ & $\begin{array}{c}\text { Volume } \\
\left(\mathrm{cm}^{3} \cdot \mathrm{g}^{-1}\right)\end{array}$ & $\begin{array}{c}\text { Pore diameter } \\
(\AA)\end{array}$ \\
\hline $\mathrm{Cr}_{2} \mathrm{O}_{3}$ & 105.6 & 0.573 & 217.0 \\
$\mathrm{Fe}_{2} \mathrm{O}_{3}$ & 19.4 & 0.092 & 189.6 \\
\hline
\end{tabular}

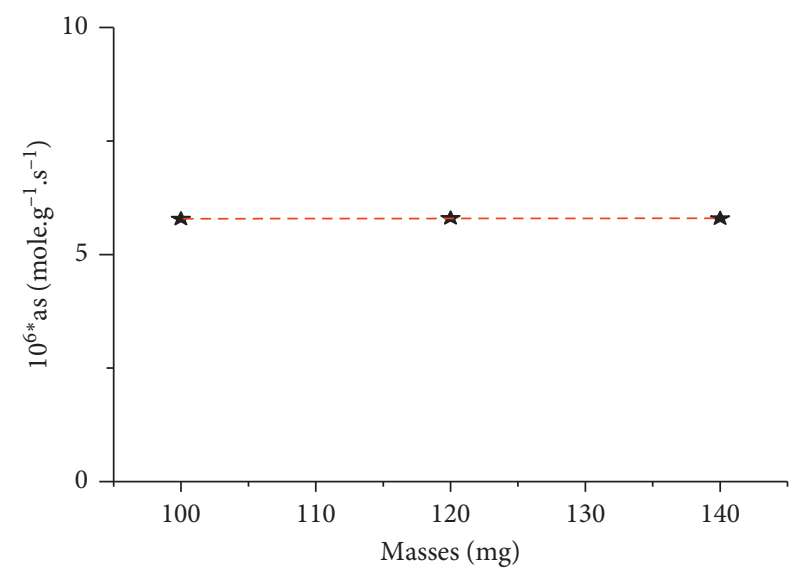

FIGURE 4: Effect of catalyst masses on the specific activity.

operating conditions, make it possible to completely convert isopropanol into $\mathrm{CO}_{2}$, after a period of 60-110 minutes, depending on the catalyst and the reaction temperature. This time decreases with temperature increasing and at constant temperature, from iron oxide to chromium oxide; so, it is possible to conclude from analysis of Figure 5 curves that chromium oxide has a best potential for catalytic total oxidation of isopropanol. Indeed, whatever the reaction temperature, the specific activity is larger for chromium oxide (Table 2) $[19,20]$. The difference can be related to the solid's nature and its well-developed texture (Table 1).

\subsection{Kinetics and Mechanism of the Reaction}

3.3.1. Variation of $T T_{a c}$ and $T T_{C O 2}$ versus $T T_{G}$. $T_{\mathrm{g}}$ is the global conversion of isopropanol: $\mathrm{TT}_{\mathrm{G}}=\left(\mathrm{n}_{0}-\mathrm{n}\right) / \mathrm{n}_{0}$; $\mathrm{TT}_{\mathrm{act}}=\mathrm{n}_{\mathrm{ac}} / \mathrm{n}_{0}$; and $\mathrm{TT}_{\mathrm{CO} 2}=\mathrm{TT}_{\mathrm{g}}-\mathrm{TT}_{\mathrm{ac}} \cdot n$ and $\mathrm{n}_{\mathrm{ac}}$ are, respectively, the moles number of isopropanol acetone at time $t$. $n_{0}$ is the moles number of isopropanol at time $t=0$.

Figure 6 curves represent evolution of acetone yield $\mathrm{TT}_{\mathrm{act}}$ and $\mathrm{CO}_{2}$ yield $\mathrm{TT}_{\mathrm{CO} 2}$ versus $\mathrm{TT}_{\mathrm{G}}$ at all temperatures tested in case of $\mathrm{Cr}_{2} \mathrm{O}_{3}$ catalyst [21].

These curves show that oxidation of isopropanol into carbon dioxide is complete at all working temperatures 40 , 60 , and $80^{\circ} \mathrm{C}$ for a reaction time not exceeding $110 \mathrm{~min}$. The secondary product formed is acetone, which passes throw à maximum for all temperatures. It should be noted that the remarkable selectivity initial extrapolated to time $0(100 \%)$, which falls to 0 when conversion is close to unity. This implies the conversion of acetone into $\mathrm{CO}_{2}$ over time, verified in this study. Furthermore, the absence of isopropylene as reaction product indicates the absence of acidic sites at a solid surface. It seems, taking account of all these findings, that isopropanol oxidation takes place according to a redox mechanism [22], which alternates catalyst oxidation and reduction steps as a general scheme [23]: 

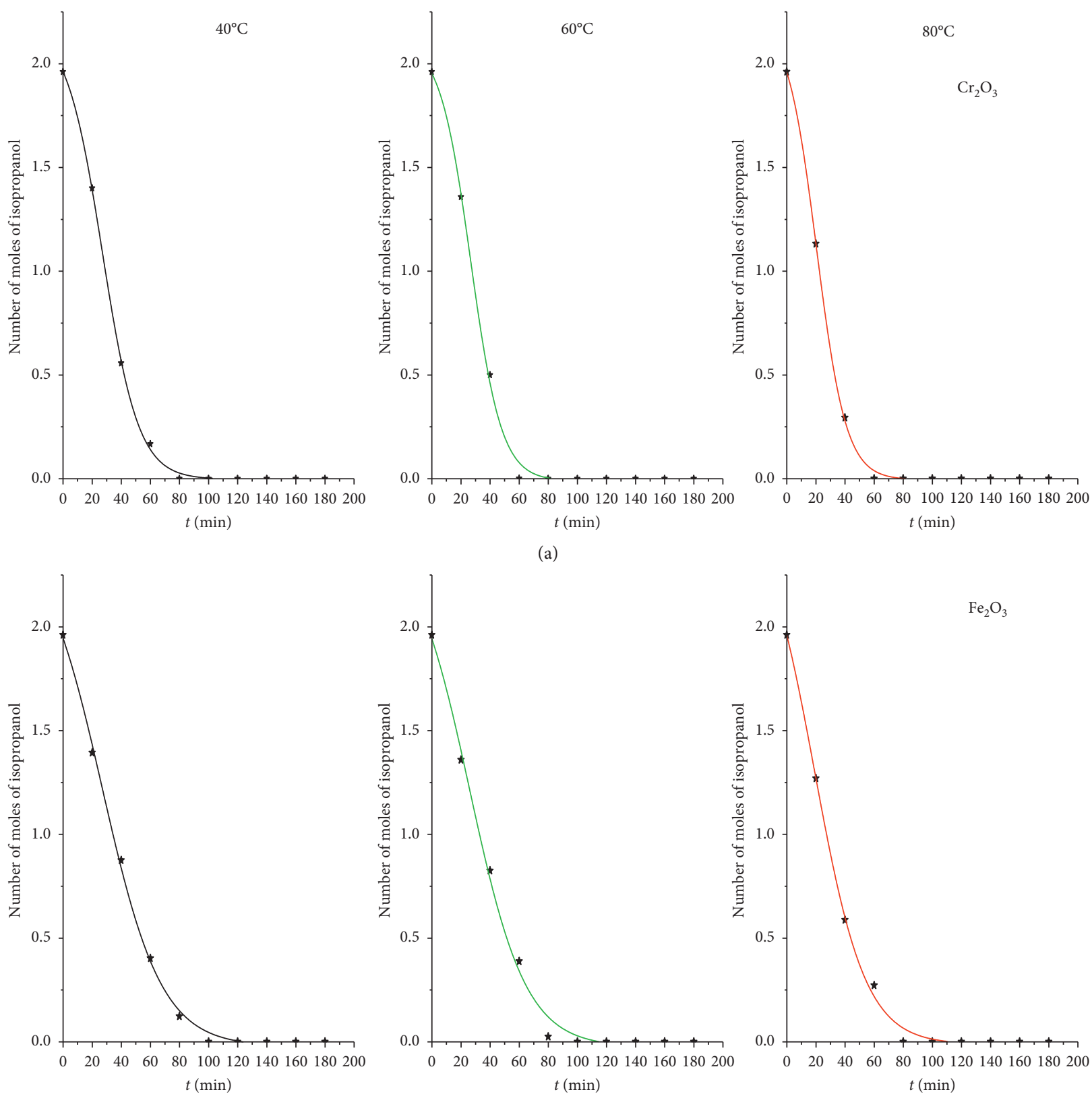

(b)

Figure 5: Moles number of isopropanol as a function of time in the presence of $\mathrm{Cr}_{2} \mathrm{O}_{3}$ and $\mathrm{Fe}_{2} \mathrm{O}_{3}$ catalysts at different temperatures.

isopropanol + oxidized catalyst $\longrightarrow$ reduced catalyst

+ oxidation products

Moreover, given the conversion of acetone into carbon dioxide over time, discussed above, this suggests a scheme of successive reaction as follows [24-32]:

$$
\text { isopropanol } \longrightarrow \text { Acetone } \longrightarrow \mathrm{CO}_{2}
$$

3.4. Apparent Activation Energy. The conversion evolution curves of isopropanol in time, at different temperatures, obtained previously, can be used to determine kinetic parameters, such as the constant speed $k$ and apparent activation energy $\left(\mathrm{E}_{\mathrm{a}}\right)$ of the oxidation reaction.

The specific activity can be expressed as $a_{\mathrm{s}}=A \exp \left(-\mathrm{E}_{\mathrm{a}} / \mathrm{RT}\right)$. $f$, where $A$ is the preexponential Arrhenius factor and $f$ is a function of active constituents' concentrations and catalyst mass.

Then, at constant concentrations and variable temperature, a leaner expression of temperature inverse can be written as follows [18]:

$$
\log \left(a_{s}\right)=\log A+\log f-\frac{\mathrm{E}_{a}}{\mathrm{RT}}
$$

Figure 7 represents $\ln \left(a_{\mathrm{s}}\right)=f(1 / T)$ right. The slope of this line led to a value of activation apparent energies: 


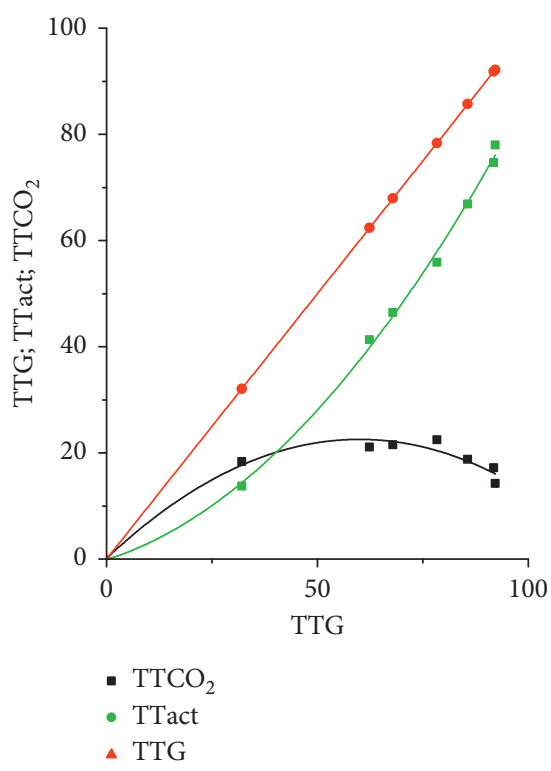

(a)

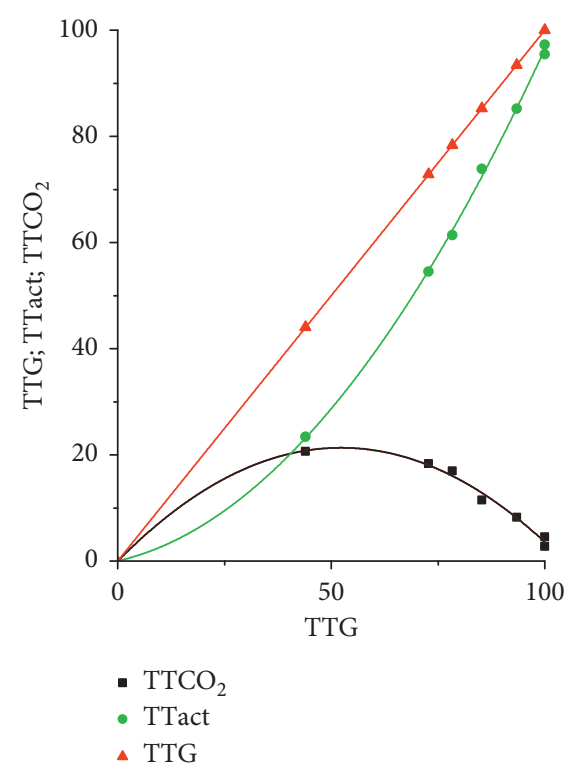

(b)

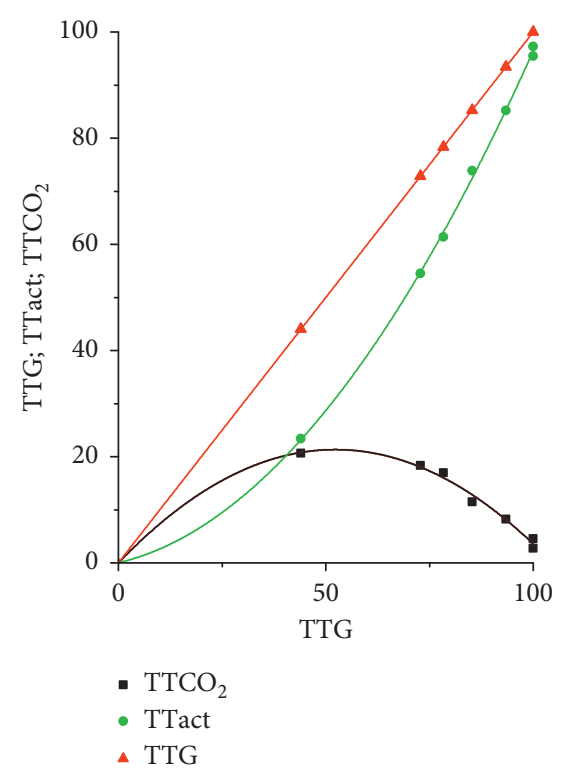

(c)

Figure 6: Evolution of $\mathrm{TT}_{\mathrm{act}}$ and $\mathrm{TT}_{\mathrm{CO} 2}$ versus $\mathrm{TT}_{\mathrm{G}}$ at different temperatures.

TABLE 2: Logarithm of the specific activity versus temperature inverse.

\begin{tabular}{lcccrc}
\hline Oxide & $T^{\circ} \mathrm{C}$ & $a_{\mathrm{s}}\left(\mathrm{mol} \cdot \mathrm{g}^{-1} \cdot \mathrm{s}^{-1}\right)$ & $v_{0}\left(\mathrm{~mol} \cdot \mathrm{s}^{-1}\right)$ & $\operatorname{Ln}\left(a_{\mathrm{s}}\right)$ & -12.23 \\
\hline \\
$\mathrm{Cr}_{2} \mathrm{O}_{3}$ & 40 & $4.87 * 10^{-06}$ & $5.85 \mathrm{E}-7$ & -12.19 & -14.35 \\
& 60 & $5.07 * 10^{-06}$ & $6.08 E-07$ & -12.06 & -14.31 \\
\hline & 80 & $5.79 * 10^{-06}$ & $6.95 E-07$ & -12.49 \\
$\mathrm{Fe}_{2} \mathrm{O}_{3}$ & 40 & $3.77 * 10^{-06}$ & $4.52 E-07$ & -12.44 & -14.61 \\
& 60 & $3.94 * 10^{-06}$ & $4.73 E-07$ & -14.56 \\
\hline
\end{tabular}

$5.32 \mathrm{~kJ} \cdot \mathrm{mol}^{-1}$ in case of iron oxide and $2.87 \mathrm{~kJ} \cdot \mathrm{mol}^{-1}$ for chromium oxide. These low values explain the relatively high values of activity observed (Table 2). The comparison of the different values of the apparent activation energies relating to disappearance of isopropanol for the two catalysts studied shows that $\mathrm{E}_{\mathrm{a}}\left(\mathrm{Cr}_{2} \mathrm{O}_{3}\right)<\mathrm{E}_{\mathrm{a}}\left(\mathrm{Fe}_{2} \mathrm{O}_{3}\right)$ [33]. 


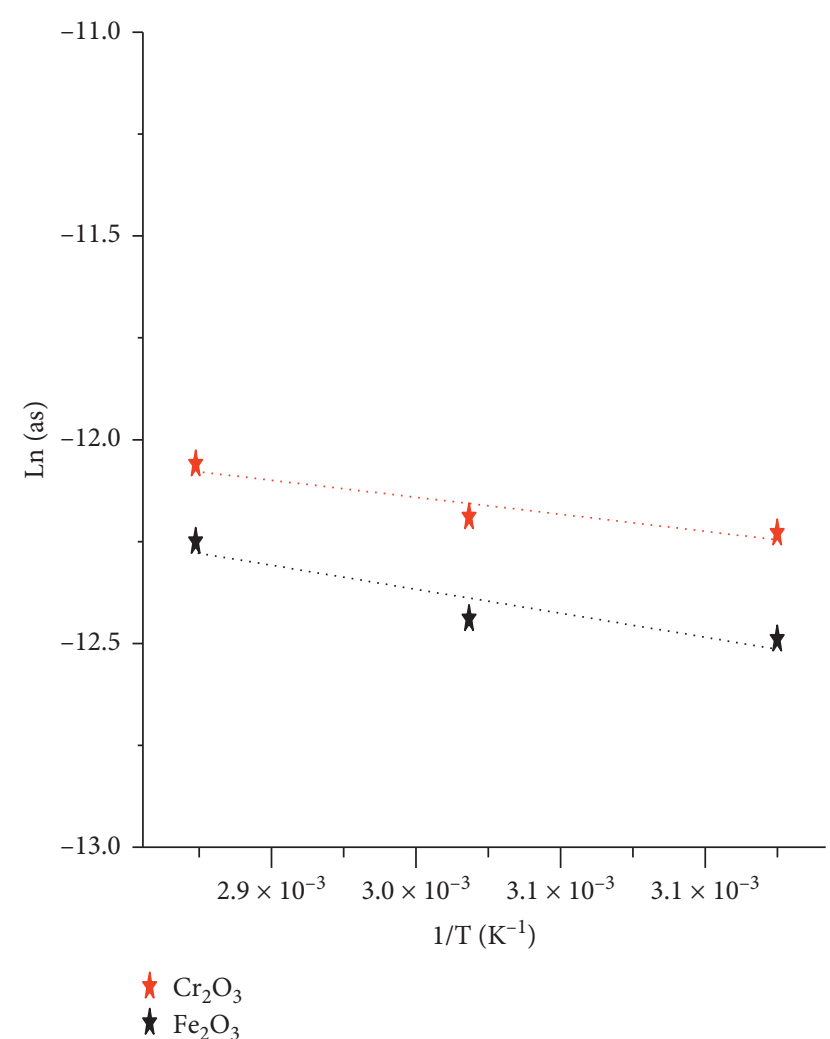

Figure 7: Logarithm of the specific activity versus temperature inverse.

\section{Conclusion}

The catalytic solids, $\mathrm{Cr}_{2} \mathrm{O}_{3}$ and $\mathrm{Fe}_{2} \mathrm{O}_{3}$, were prepared by the precipitation method and characterized by $\mathrm{X}$-ray diffraction and infrared spectroscopy; their structure matches well with those mentioned in the literature and present a good texture.

Catalytic tests conducted in the presence of these solids, in the mild temperature and pressure conditions, show a relatively high catalytic activity with respect to the total oxidation of isopropanol and a good stability over time during catalytic tests.

The two solids accuse a similar comportment catalytic with a great catalytic activity for chromium oxide related to its best texture.

Furthermore, kinetic of catalytic oxidation in the liquid phase, carried out isopropanol, showed that this reaction follows a successive mechanism: whatever the catalyst used. It should also be noted that the low value of the apparent activation energy, associated with the disappearance of isopropanol, in line with a value of the catalytic activity, is sufficiently high, in the field of temperature studied.

In sum, based on all these results, it can be concluded that oxides of chromium and iron can be used in isopropanol removal from waste water by a process involving total catalytic oxidation, which can be extended to other light alcohols.

\section{Data Availability}

All data underlying the finding of this study are fully available without restriction.

\section{Conflicts of Interest}

The authors declare that they have no conflicts of interest.

\section{References}

[1] D. Li, C. Li, and K. Suzuki, "Catalytic oxidation of VOCs over Al- and Fe-pillared montmorillonite," Applied Clay Science, vol. 77-78, pp. 56-60, 2013.

[2] P. Wonglom, S.-I. Ito, and A. Sunpapao, "Volatile organic compounds emitted from endophytic fungus Trichoderma asperellum $\mathrm{T} 1$ mediate antifungal activity, defense response and promote plant growth in lettuce (Lactuca sativa)," Fungal Ecology, vol. 43, Article ID 100867, 2020.

[3] B. Liu, W. Zhao, Q. Jiang, Z. Ao, and T. An, "Enhanced adsorption mechanism of carbonyl-containing volatile organic compounds on $\mathrm{Al}$-decorated porous graphene monolayer: a density functional theory calculation study," Sustainable Materials and Technologies, vol. 21, Article ID e00103, 2019.

[4] P. Li, S. Kim, J. Jin, H. C. Do, and J. H. Park, "Efficient photodegradation of volatile organic compounds by ironbased metal-organic frameworks with high adsorption capacity," Applied Catalysis B: Environmental, vol. 263, Article ID 118284, 2020.

[5] J. Bang, D.-W. You, Y. Jang, J.-S. Oh, and K.-W. Jung, “A carbon nanotube sponge as an adsorbent for vapor preconcentration of aromatic volatile organic compounds," Journal of Chromatography A, vol. 1605, Article ID 460363, 2019.

[6] K. Vikrant, K.-H. Kim, W. Peng, S. Ge, and Y. Sik Ok, "Adsorption performance of standard biochar materials against volatile organic compounds in air: a case study using benzene and methyl ethyl ketone," Chemical Engineering Journal, vol. 387, Article ID 123943, 2020.

[7] R. Hu, G. Liu, H. Zhang, H. Xue, X. Wang, and P. K. S. Lam, "Odor pollution due to industrial emission of volatile organic compounds: a case study in Hefei, China," Journal of Cleaner Production, vol. 246, Article ID 119075, 2020.

[8] X. Li, L. Zhang, Z. Yang, P. Wang, Y. Yan, and J. Ran, "Adsorption materials for volatile organic compounds (VOCs) and the key factors for VOCs adsorption process: a review," Separation and Purification Technology, vol. 235, Article ID 116213, 2020.

[9] M. S. Kamal, S. A. Razzak, and M. M. Hossain, "Catalytic oxidation of volatile organic compounds (VOCs) - a review," Atmospheric Environment, vol. 140, pp. 117-134, 2016.

[10] R. Beauchet, P. Magnoux, and J. Mijoin, "Catalytic oxidation of volatile organic compounds (VOCs) mixture (isopropanol/ o-xylene) on zeolite catalysts," Catalysis Today, vol. 124, no. 34, pp. 118-123, 2007.

[11] D. Kulkarni and I. E. Wachs, "Isopropanol oxidation by pure metal oxide catalysts: number of active surface sites and turnover frequencies," Applied Catalysis A: General, vol. 237, no. 1-2, pp. 121-137, 2002.

[12] Y. Dehmani and S. Abouarnadasse, "Study of the adsorbent properties of nickel oxide for phenol depollution," Arabian Journal of Chemistry, vol. 13, no. 5, pp. 5312-5325, 2020.

[13] Y. Dehmani, A. Ed-Dra, O. Zennouhi et al., "Chemical characterization and adsorption of oil mill wastewater on Moroccan clay in order to be used in the agricultural field," Heliyon, vol. 6, no. 1, Article ID e03164, 2020. 
[14] X. Xu, J. Wu, N. Yang et al., " $\mathrm{Cr}_{2} \mathrm{O}_{3}$ : a novel supercapacitor electrode material with high capacitive performance," $M a$ terials Letters, vol. 142, pp. 172-175, 2015.

[15] Y. Dehmani, A. A. Alrashdi, H. Lgaz, T. Lamhasni, S. Abouarnadasse, and I.-M. Chung, "Removal of phenol from aqueous solution by adsorption onto hematite $\left(\alpha-\mathrm{Fe}_{2} \mathrm{O}_{3}\right)$ : mechanism exploration from both experimental and theoretical studies," Arabian Journal of Chemistry, vol. 13, no. 5, pp. 5474-5486, 2020.

[16] S. M. Abbas, N. Ahmad, Ata-ur-Rehman et al., "High rate capability and long cycle stability of $\mathrm{Cr}_{2} \mathrm{O}_{3}$ anode with CNTs for lithium ion batteries," Electrochimica Acta, vol. 212, pp. 260-269, 2016.

[17] S. Mobini, F. Meshkani, and M. Rezaei, "Synthesis and characterization of nanocrystalline copper-chromium catalyst and its application in the oxidation of carbon monoxide," Process Safety and Environmental Protection, vol. 107, pp. 181-189, 2017.

[18] H. Sahraoui, S. Abouarnadasse, K. Elkamel, A. Nadiri, and A. Yacoubi, "Étude de l'activité catalytique d'une diatomite naturelle marocaine dans la réaction de décomposition de l'isopropanol," Annales de Chimie Science des Matériaux, vol. 28, no. 4, pp. 91-105, 2003.

[19] S. Abouarnadasse, G. M. Pajonk, S. J. Teichner, and J. E. Germain, "Mixed nickel-aluminium oxides catalysts for the nitroxidation of toluene by NO into benzonitrile," The Canadian Journal of Chemical Engineering, vol. 62, no. 4, pp. 521-525, 1984.

[20] M. K. Younes and A. Ghorbel, "Catalytic nitroxidation of toluene into benzonitrile on chromia-alumina aerogel catalyst," Applied Catalysis A: General, vol. 197, no. 2, pp. 269-277, 2000

[21] S. Abouarnadasse, G. M. Pajonk, J. E. Germain, and S. J. Teichner, "Catalytic nitroxidation of toluene into benzonitrile over nickel oxide-alumina xero- or aero-gel catalysts," Applied Catalysis, vol. 9, pp. 119-128, 1984.

[22] R. Beauchet, J. Mijoin, I. Batonneau-Gener, and P. Magnoux, "Catalytic oxidation of VOCs on NaX zeolite: mixture effect with isopropanol and o-xylene," Applied Catalysis B: Environmental, vol. 100, no. 1-2, pp. 91-96, 2010.

[23] C. Lahousse, J. Bachelier, J.-C. Lavalley, H. Lauron-Pernot, and A.-M. Le Govic, "Validity of using isopropanol decomposition as a test-reaction for the characterization of metal oxides basicity; comparison with results obtained from methylbutynol decomposition," Journal of Molecular Catalysis, vol. 87, no. 2-3, pp. 329-332, 1994.

[24] N. Hussain, S. Tufail, H. Sherazi et al., "Applied Catalysis A : general Synthesis of 1 -methionine stabilized nickel nanowires and their application for catalytic oxidative transfer hydrogenation of isopropanol," Applied Catalysis A, General, vol. 400, pp. 215-220, 2011.

[25] E. H. Calderon, J. Hahladakis, G. Foti, and A. Katsaounis, "Effectiveness factor of isopropanol oxidation on $\mathrm{IrO} 2$ based electrodes of different loading," Electrochimica Acta, vol. 55, no. 27, pp. 8215-8219, 2010.

[26] J. Medina-Valtierra, C. Frausto-Reyes, G. CamarilloMartínez, and J. A. Ramírez-Ortiz, "Complete oxidation of isopropanol over $\mathrm{Cu}_{4} \mathrm{O}_{3}$ (paramelaconite) coating deposited on fiberglass by CVD," Applied Catalysis A: General, vol. 356, no. 1, pp. 36-42, 2009.

[27] G. Luis, "Isopropanol adsorption-oxidation over V2O5-A mass spectrometry study," Journal of Molecular Catalysis A: Chemical, vol. 247, no. 1-2, pp. 31-35, 2006.
[28] R. M. Rioux and M. A. Vannice, "Hydrogenation/dehydrogenation reactions: isopropanol dehydrogenation over copper catalysts," Journal of Catalysis, vol. 216, no. 1-2, pp. 362-376, 2003.

[29] J. Karuppiah, L. Sivachandiran, R. Karvembu, and C. Subrahmanyam, "Catalytic nonthermal plasma reactor for the abatement of low concentrations of isopropanol," Chemical Engineering Journal, vol. 165, no. 1, pp. 194-199, 2010.

[30] P. Manoj Kumar Reddy, K. Krushnamurty, and C. Subrahmanyam, "Surface modification of carbon fabric for isopropanol removal from gas stream," Microelectronic Engineering, vol. 126, pp. 60-64, 2014.

[31] J. Bedia, J. M. Rosas, D. Vera, J. Rodríguez-Mirasol, and T. Cordero, "Isopropanol decomposition on carbon based acid and basic catalysts," Catalysis Today, vol. 158, no. 1-2, pp. 89-96, 2010.

[32] Y. Yan, L. Wang, H. Zhang, and X. Zhang, "Catalytic combustion of isopropanol over Co-Mn mixed oxides modified ZSM-5 zeolite membrane catalysts coated on stainless steel fibers," Separation and Purification Technology, vol. 175, pp. 213-221, 2017.

[33] I. Ismagilov, E. Michurin, O. Sukhova et al., "Oxidation of organic compounds in a microstructured catalytic reactor," Chemical Engineering Journal, vol. 135, pp. S57-S65, 2008. 